\title{
CHEMICAL AND SPECTROSCOPIC EVIDENCE FOR SPECIFIC ADSORPTION OF CHROMATE ON HYDROUS IRON OXIDE
}

\author{
Hsia, T. H.*, S. L. Lo*, C. F. Lin* and D. Y. Lee** \\ ${ }^{*}$ Graduate Institute of Environmental Engineering, National Taiwan University \\ **Department of Agricultural Chemistry, National Taiwan University
}

(Received in Germany 9 December 1992; accepted 1 March 1993)

\begin{abstract}
The adsorption of chromate from aqueous solution was investigated to understand the binding characteristics of chromate on hydrous iron oxide. Both chemical and spectroscopic analyses (EDAX, Energy Dispersive Analysis of X-Ray and FTIR, Fourier Transform Infrared) were used for characterizing the chromate adsorption sites on hydrous iron oxide. The zeta potential measurements were conducted for observation of the shift in isoelectric point of the system containing iron oxide suspension and various concentrations of chromate. The isoelectric point of the system containing more chromate was a few $\mathrm{pH}$ units lower than that of the system containing less chromate or no chromate. This phenomenon was attributed to an increase in the negative charge of the iron oxide surface as a result of adsorption of chromate. An inner-sphere coordination of chromate to iron oxide surface was identified from EDAX and FTIR results. Specific adsorption was therefore required to occur at the aqueous chromate anion and iron oxide interfaces.
\end{abstract}

\section{INTRODUCTION}

Spectroscopic techniques have been used for characterizing the binding mechanism between adsorbate ions and metal oxide surface. Infrared spectroscopy was utilized by both Serna et al. ${ }^{(1)}$ and Harrison and Berkheiser ${ }^{(2)}$ for formulation of adsorption mechanism for various anions with aluminum hydroxides and hydrous iron oxides, respectively. FTIR was further used by Ho and Miller ${ }^{(3)}$ for characterizing the sorption products of uranyl species adsorbed onto hematite particles. Raman and infrared spectroscopy were extensively utilized by White and Hem ${ }^{(4)}$ for determination of the relationship between the carbonate ion and $\mathrm{Al}(\mathrm{OH})_{3}$. Infrared technique was also used by Parffit et al. ${ }^{(5)(6)}$ for demonstrating that when phosphate is adsorbed on iron oxide surface, the binuclear bridging complex is formed. Sulfate, although more weakly adsorbed than phosphate, has been previously shown by Parffit and Russel ${ }^{(7)}$ and Parffit and Smart ${ }^{(8)}$ to form a similar binuclear complex on goethite.

Isoelectric point determinations have been previously used for verification of specific or nonspecific adsorption of adsorbate ions. A lowering of the isoelectric points of goethite and gibbsite with specifically adsorbed anions was observed to occur by Hingston et al. ${ }^{(9)(10)}$. Feldkamp et al. ${ }^{(11)}$ showed. that the isoelectric point of $\mathrm{Al}(\mathrm{OH})_{3}$ sorbent containing specifically adsorbed carbonate was lower 
than that without carbonate. Stumm ${ }^{(12)}$ also indicated that specifically adsorbed anions (cations) decrease (increase) the $\mathrm{pH}$ of the isoelectric point.

Chromate adsorption on metal oxide surface has been studied by several researchers ${ }^{(13)(14)(15)}$. These studies have, however, been limited by a lack of direct evidence by which chromate adsorption sites on oxide surface may be characterized. This work has combined chemical and spectroscopic analyses making a characterization of the adsorption type for aqueous chromate onto hydrous iron oxide surface.

\section{MATERIALS AND METHODS}

\section{Preparation of Hydrous Iron Oxide}

Hydrous iron oxide was prepared in batch through an addition of a $0.1 \mathrm{~N}$ ferric nitrate stock solution to Milli-Q water at $25^{\circ} \mathrm{C}$ under a nitrogen atmosphere. $0.01 \mathrm{~N} \mathrm{NaNO}_{3}$ solution was used as background electrolyte in maintaining an approximately constant ionic strength. Hydrous iron oxide was precipitated by a dropwise addition of $0.1 \mathrm{~N} \mathrm{NaOH}$ solution until a $\mathrm{pH}$ of 8.0 was attained ${ }^{(13)}$. The hydrous iron oxide prepared by this procedure was verified to be amorphous by X-ray diffraction analysis. The iron oxide slurry was aged at $\mathrm{pH} 8.0 \pm 0.2$ for 2 hours before the adsorption experiments were initiated.

\section{Adsorption Experiment}

The $\mathrm{pH}$ of the suspension was adjusted for the batch type of equilibrium adsorption experiment with small amounts of $\mathrm{HNO}_{3}$ or $\mathrm{NaOH}$. This was done for the sake of covering the $\mathrm{pH}$ range from 4 to 10 at the end of aging period. A $50 \mathrm{ml}$ aliquot of suspension was transferred at each adjusted $\mathrm{pH}$ point to a Pyrex glass vessel and chromate was then added to the system to attain the desired total concentration. These vessels were also under $\mathrm{N}_{2}$ atmosphere, $25^{\circ} \mathrm{C}$ and the $\mathrm{pH}$ remained constant during the equilibration period. Solid and liquid were separated by $0.2 \mu \mathrm{m}$ membrane filtration after 2 hours equilibration time. The concentrations of chromate of samples of filtrates were analyzed by ion chromatography using Dionex model 2000i/SP equipped with HPIC-CS5 separator column. All analytical conditions were run at a pump rate of $1.5 \mathrm{ml} / \mathrm{min}$ using an eluent of PDCA(pyridine dicarboxylic acid) based.

\section{Zeta Potential Measurements}

Zeta potential was analyzed in this work using Photal OTSUKA Electronics Model: ELS-800 Electrophoretic Light Scattering. This instrument has used laser light for simultaneous measurement of several particles' mobility and generation of mobility histogram. Mobility could be automatically converted into zeta potential. Oxide suspension of $\mathrm{Fe}(\mathrm{III})=1.0 \times 10^{-3} \mathrm{M}$ and three various chromate concentrations were prepared in a batch for zeta potential measurements. $\mathrm{NaNO}_{3}$ was used as background electrolyte in maintaining an ionic strength of $0.01 \mathrm{M}$. After adsorption equilibrium, $20 \mathrm{ml}$ of oxide suspension was transferred to a sample tube. Zeta potential of the oxide suspension was then measured by electrokinetic analysis.

\section{EDAX and FTIR Analyses}

All oxide suspension samples observed in the EDAX and FTIR were eluted several times with Milli-Q water to ensure that the electric conductivity of supernatant of sample was approximately to equal that of Milli-Q water. Almost no electrolytes and adsorbate ions were therefore present in aqueous phase. Centrifugation and freeze-drying were respectively used for separation of the solid/aqueous phases and drying the solid samples. All freeze-dried solid samples were then analyzed by the EDAX (Hitachi-S-2400 Scanning Electronic Microscope with a EDAX KEVEX Level 4) and FTIR(Bio-Rad FTS 7PC Spectrometer). The operational conditions for EDAX analysis were scanning energy from 0 to $10.23 \mathrm{keV}$, with an elapsed time of 100 seconds. All samples in FTIR analysis were prepared in a pellet form. The pellets were a mixture of $\mathrm{KBr}$ and freeze-dried samples placed in a 
die in which 10 tons were applied under vacuum for 5 minutes. The operational conditions for FTIR analysis were a scanning wavenumber from 400 to $4000 \mathrm{~cm}^{-1}$, scanning 32 times .

\section{RESULTS AND DISCUSSION}

\section{Adsorption of Chromate on Hydrous Iron Oxide}

Adsorption edges of various chromate concentrations on hydrous iron oxide surface are illustrated in Figure 1. The adsorption efficiency is strongly dependent on $\mathrm{pH}$ with the greater adsorption occuring at the lower $\mathrm{pH}$ regions. These results are consistent with those previously reported by Aoki $^{(14)}$ and Zachzra ${ }^{(15)}$. Surface protonation is believed to increase positively charged sites, enhancing the attraction force between $\mathrm{Cr}$ anions and iron oxide surface and therefore raising the amount of chromate adsorbed on solid surface.

The chromate adsorption densities on hydrous iron oxide are shown in Figure 2. Raising the concentration of chromate is indicated in this figure to increase adsorption density on solid surface. This phenomenon can be accounted for that increasing of reactant concentration should shift the reaction towards the product side. The concentration of solid complexes increases as the concentration of aqueous chromate raises. The adsorption density on solid surface increases as adsorbate concentration increases.

Above experiments provide no evidence to support the adsorption type in solid/liquid interfaces owing to only an adsorption percentage was obtainable.

\section{Zeta Potential Measurements}

The specific adsorption of anions makes the colloid surface more negatively charged. The greater the adsorption of anions, the greater the net negative charge added to the colloid surface. This results in a shift in the isoelectric point to a lower $\mathrm{pH}$ value. The isoelectric point is therefore an important parameter for characterizing adsorption type of ions and solid surface.

A lowering of the isoelectric point of the system should be observed; that is, if chromate was specifically adsorbed on hydrous iron oxide. The zeta potential measurements of iron oxide suspensions containing various chromate concentrations have been shown in Figure 3. The isoelectric point for the hydrous iron oxide free of any specifically adsorbed anion $\left(\mathrm{pH}_{\text {iep }}=\mathrm{pH}_{\mathrm{zpc}}\right.$, zero point of charge) was about 8.1. This is in close agreement with Parks ${ }^{(16)}$ and Yates ${ }^{(17)}$ who reported the isoelectric point for a similar slurry to be 7.9 and 8.1 which is typical of this hydrous iron oxide in which $\mathrm{H}^{+}$and $\mathrm{OH}^{-}$are the only potential determining ions. The systems that contain chromate of $5.0 \times 10^{-5} \mathrm{M}, 1.0 \times 10^{-4} \mathrm{M}, 2.0 \times 10^{-4} \mathrm{M}$ have isoelectric points of about $7.2,5.6,4.8$, respectively. This was a drop of more $\mathrm{pH}$ units from the isoelectric point of the system without chromate as chromate surface coverage raised. Specific adsorption can therefore be indicated from a shift in isoelectric point to necessarily be present in aqueous chromate and on iron oxide surface.

\section{EDAX and FTIR Analyses}

The EDAX technique can provide more useful information about interaction between aqueous chromate and solid iron oxide. The EDAX spectra for systems with various chromate concentrations and free of chromate are illustrated in Figure 4. Constituent ratios measured by the EDAX technique are shown in Table 1.

Table 1. Molar ratios measured by $\operatorname{EDAX}\left(\mathrm{Fe}(\mathrm{III})=2.0 \times 10^{-3} \mathrm{M}, \mathrm{pH}=4.0\right)$

\begin{tabular}{ccc}
\hline chromate concentration & weight ratio( $\mathrm{Cr} / \mathrm{Fe})$ & molar ratio $(\mathrm{Cr} / \mathrm{Fe})$ \\
\hline $2.67 \times 10^{-3} \mathrm{M}$ & $10.11 / 89.89$ & $10.78 / 89.22$ \\
$2.0 \times 10^{-3} \mathrm{M}$ & $9.52 / 90.48$ & $10.16 / 89.84$ \\
$1.0 \times 10^{-3} \mathrm{M}$ & $8.50 / 91.50$ & $9.07 / 90.93$ \\
\hline
\end{tabular}

Only Fe signal can be observed in Figure 4(a). Fe is well known to be the principal element of freeze-dried sample of iron oxide suspension without chromate. Although a high concentration of 


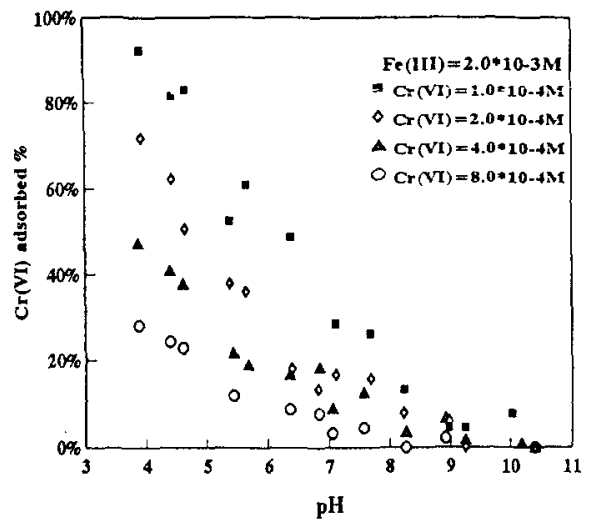

Figure 1. $\mathrm{Cr}(\mathrm{VI})$ adsorption edges of hydrous iron oxide in $0.01 \mathrm{H}$ $\left.\mathrm{NaNO}{ }_{3}, \mathrm{Fe} \| I I I\right)=2.0 * 10^{-3} \mathrm{M}$. $\dot{\mathrm{Cr}}(\mathrm{VI})=1.0,2.0,4.0,8.0$ $* 10^{-4} \mathrm{M}$.

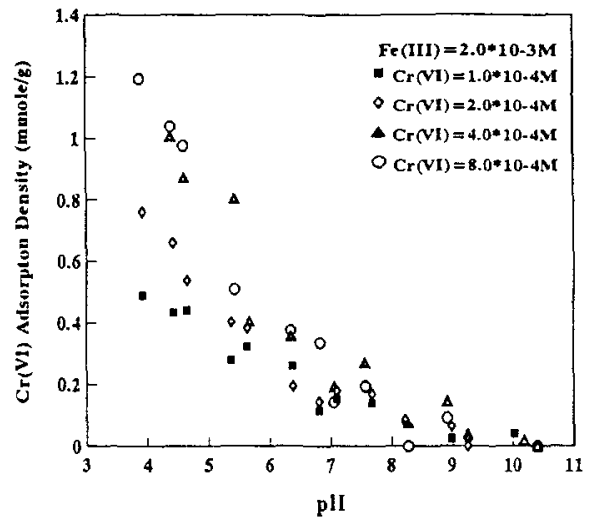

Figure 2. $\mathrm{Cr}(\mathrm{VI})$ adsorption densities on hydrous iron oxide in $0.01 \mathrm{M}$ $\mathrm{NaNO}_{3}, \quad \mathrm{Fe}(I I)=2.0^{*} 10^{-3} \mathrm{M}$. $\mathrm{Cr}(\mathrm{VI})=1.0,2.0,4.0,8.0$ $* 10^{4} \mathrm{M}$.

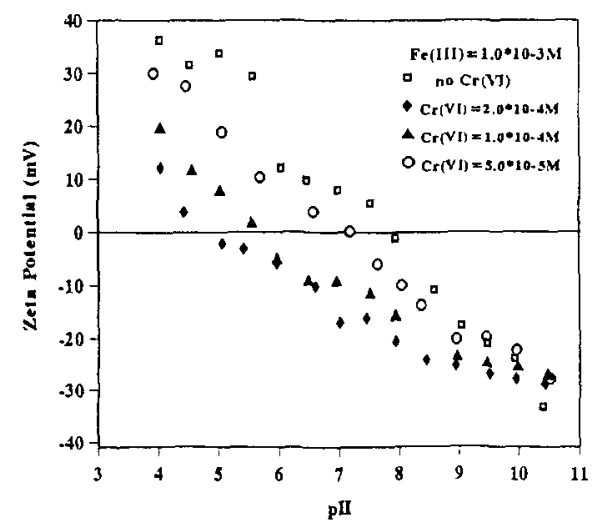

Figure 3. Zeta potential of hydrous iron oxide, $\mathrm{Fe}(\mathrm{III})=1.0^{*} 10^{-3} \mathrm{M}, \mathrm{Cr}$ VI $)$ $=0,5.0^{*} 10^{-5} \mathrm{M}, \quad 1.0^{*} 10^{-4} \mathrm{M}, \quad 2.0^{*} 10^{-4} \mathrm{M}$. 


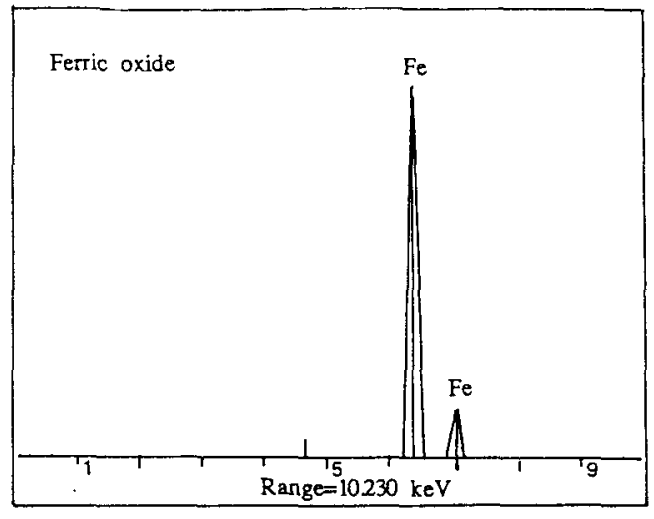

(a)

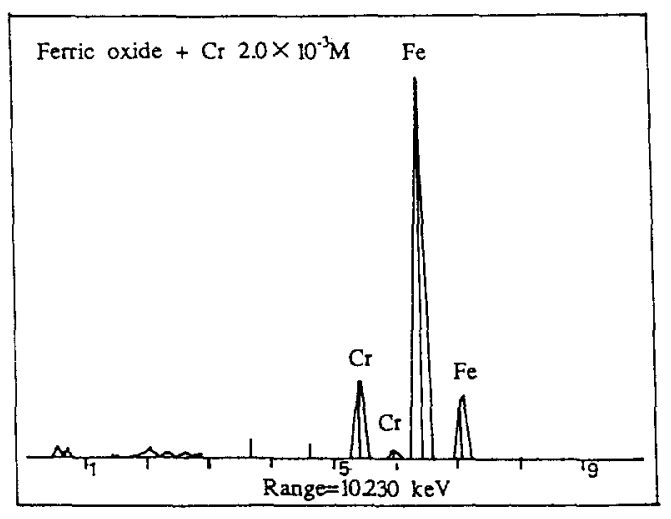

(c)

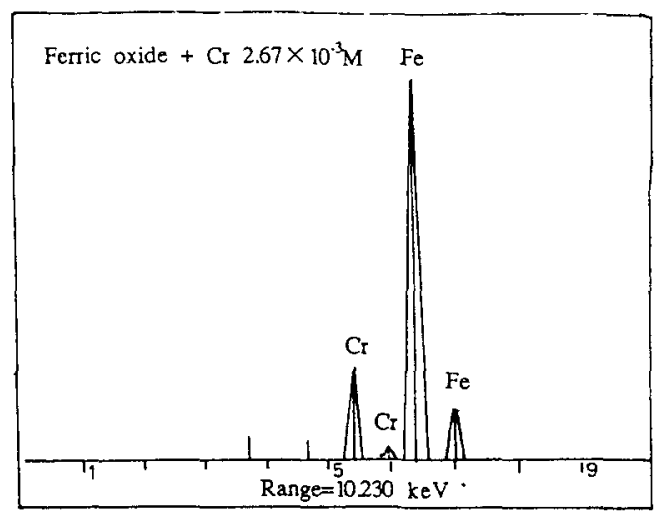

(b)

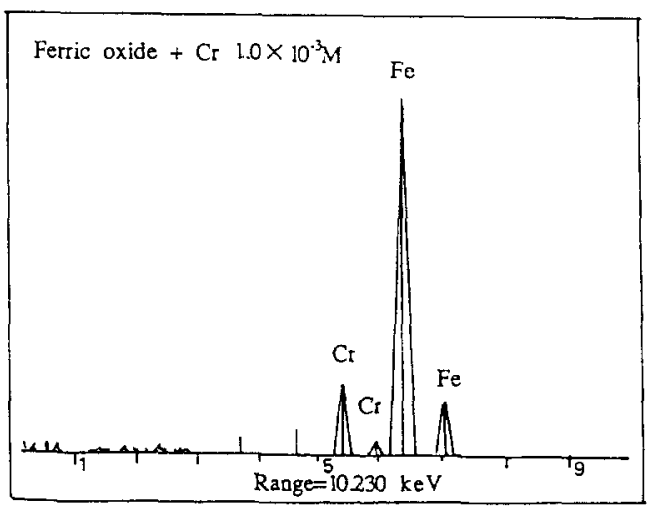

(d)

Figure 4. EDAX spectra of hydrous iron oxide( $\left.\mathrm{Fe}(\mathrm{III})=2.0^{*} 10^{-3} \mathrm{MI}\right)$ with (a) $\operatorname{Cr}(\mathrm{VI})=0$, (b) $\left.\mathrm{Cr}_{\mathrm{r}} \mathrm{VI}\right)=2.67^{*} 10^{-3} \mathrm{M}$, (c) $\mathrm{Cr}(\mathrm{VI})=2.0^{*} 10^{-3} \mathrm{M}$.

(d) $\mathrm{Cr}(\mathrm{VI})=1.0 * 10^{-3} \mathrm{MI}$ 


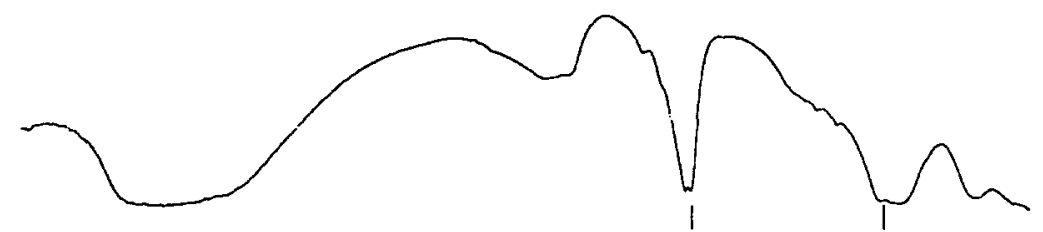

$b$
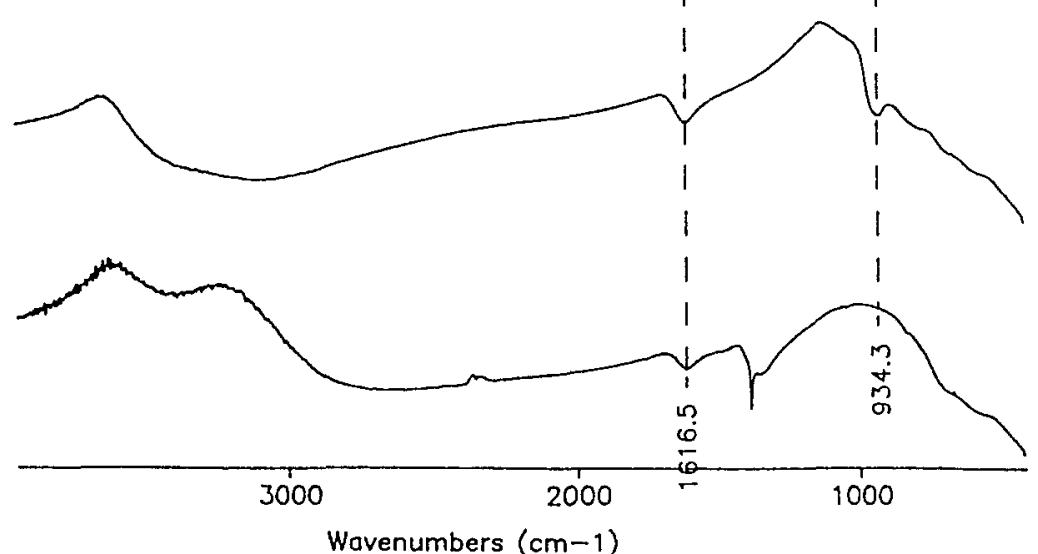

Rege $4 \mathrm{~cm}-1$

Figure 5. FTrR spectra of (a) sodium chromate, $\mathrm{Na}_{2} \mathrm{CrO}_{4} 4 \mathrm{H}_{2} \mathrm{O}$, (b) iron oxide with $\mathrm{Cr}(\mathrm{VI})=2.67^{*} 10^{-3} \mathrm{M}$, (c)iron oxide without $\mathrm{Cr}(\mathrm{VI})$.

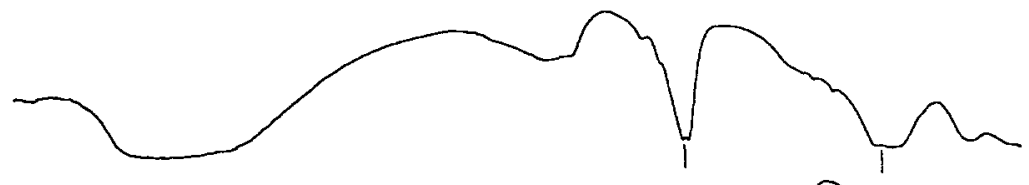

$b$

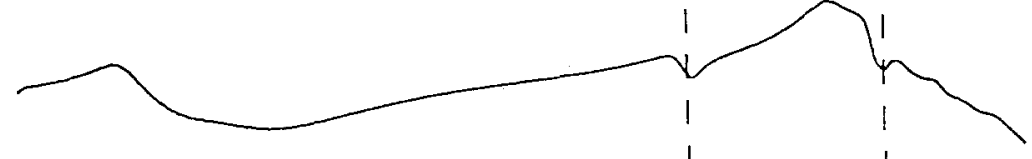

c

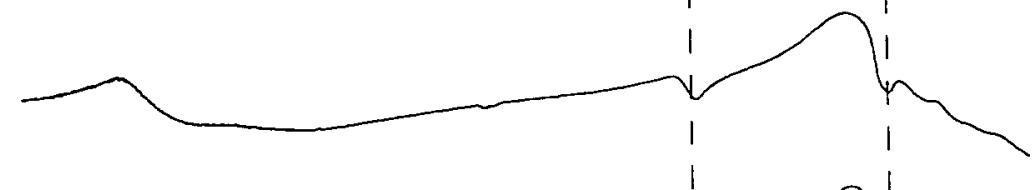

$d$

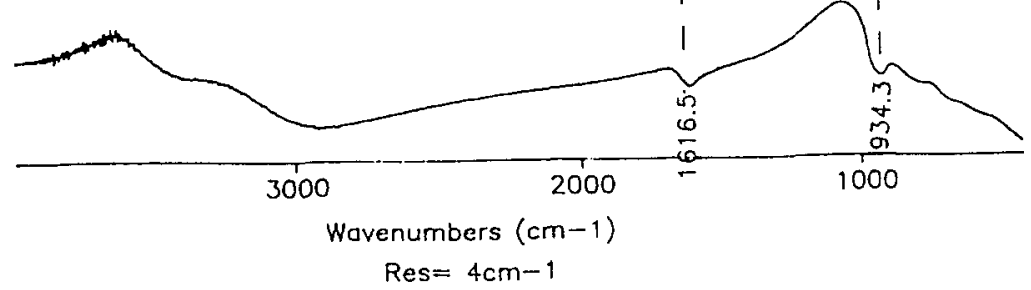

Figure 6. FTIR spectra of (a) sodium chromate, $\mathrm{Na}_{2} \mathrm{CrO}_{4} \cdot 4 \mathrm{H}_{2} \mathrm{O}$ (b) iron oxide with $\operatorname{Cr}(\mathrm{VI})=2.67 * 10^{\circ} \cdot \mathrm{M}$, (c) iron oxide with $\mathrm{Cr}(\mathrm{VI})=$ $2.0^{*} 10^{* 3} \mathrm{M}$, (d) iron oxide with $\operatorname{Cr}(\mathrm{VI})=1.0^{*} 10^{-3} \mathrm{M}$. 
background electrolyte $\mathrm{NaNO}_{3}$ is in aqueous phase, no signals of $\mathrm{N}$ and $\mathrm{Na}$ are found in this spectrum. The result clearly indicates that the nonspecific adsorbing ions of $\mathrm{Na}^{+}$and $\mathrm{NO}_{3}^{-}$are washed out from the surface through elution process with Milli- $Q$ water. Cr is shown from the results in Figure 4 (b), Figure 4(c) and Figure 4(d) to become the principal element of the samples except Fe and still no N and $\mathrm{Na}$ signals are found in these spectra. This is due to the fact that chromate is chemisorbed on iron oxide surface. The molar ratio of $\mathrm{Cr} / \mathrm{Fe}$ in solid iron oxide samples is seen from a comparison of the data in Table 1 to increase with a raising aqueous chromate concentration. EDAX analyses therefore provide the direct evidence for the results observed in Figure 2 and the supporting evidence for specific adsorption of chromate on hydrous iron oxide surface.

Positive identification of adsorbed chromate was attained using FTIR technique. The infrared spectra of sodium chromate, hydrous iron oxide adsorbing chromate and iron oxide free of chromate are given in Figure 5. Free chromate ion has been indicated from the assignments and nomenclature of Nakamoto ${ }^{(18)}$ to contain two bands designated as $\nu_{3}\left(890 \mathrm{~cm}^{-1}\right)$ and $\nu_{4}\left(378 \mathrm{~cm}^{-1}\right)$ vibrations. The FTIR spectrum of sodium chromate is shown in Figure 5(a). The main absorption bands are observed at $1616 \mathrm{~cm}^{-1}$ and doublet $935 \mathrm{~cm}^{-1}$ and $885 \mathrm{~cm}^{-1}$. The absorption frequencies of this doublet are in close agreement with the $\nu_{3}$ value previously reported by Nakamoto, $950 \sim 800 \mathrm{~cm}^{-1}$ by White ${ }^{(19)}$ and $950 \sim 770 \mathrm{~cm}^{-1}$ by Socrates ${ }^{(20)}$. A shifit of absorption bands should occur if the symmetry of the ion is lowered by interaction with hydrous iron oxide. Chromate interacts with iron oxide surface by chemical bonding, as indicated by a comparison of the spectra before and after the adsorption of chromate. Following adsorption of chromate, the absorption band at $934.3 \mathrm{~cm}^{-1}$ which is not observed in the original spectrum of iron oxide arises and band at $1616 \mathrm{~cm}^{-1}$ enhances in the spectrum of iron oxide. These bands slightly shift from those observed in the spectrum of sodium chromate. This is due to the fact that the symmetry of chromate ion is lowered after adsorption reaction. The spectra of sodium chromate and iron oxide with three surface chromate loadings are shown in Figure 6. Similar absorption bands can be observed in the spectra of iron oxide adsorbing three different chromate concentrations. Specific adsorption can be concluded according to the FTIR spectrum analyses results to be required to occur at aqueous chromate and solid iron oxide interface.

\section{CONCLUSIONS}

Chromate was indicated by the adsorption experimental data to be adsorbed onto the surface of the hydrous iron oxide. Zeta potential measurements exhibited a lowering of the isoelectric point of the hydrous iron oxide system as a result of adsorbed chromate. $\mathrm{Cr}_{r}$ was shown by EDAX results to be the principal constituent of iron oxide after adsorption, suggesting that chromate is chemisorbed onto iron oxide surface. Chromate absorption bands were indicated by FTIR spectral data to arise and slightly shift on the spectrum of iron oxide, again verifying that chromate could specifically adsorb on iron oxide surface. Specific adsorption could therefore be concluded on the basis of chemical and spectroscopic analyses to occur at the aqueous chromate and solid iron oxide interface.

\section{ACKNOWLEDGEMENTS}

The authors express their gratitude to the National Science Council, Taiwan, R. O. C. for its financial support. (Contract No: NSC 81-0410-E-002-34).

\section{REFERENCES}

1. Serna, C. J., J. L. White and S. L. Hem, Soil Sci. Soc. Am. J., 1977, 41,1009-1013.

2. Harrison, J. B. and V. E. Berkheiser, Clays Clay Miner., 1982, 30, 97-102. 
3. Ho, C. H. and N. H. Miller, J. Colloid Interface Sci., 1985, 110, 165-171.

4. White, J. L. and S. L. Hem, J. Pharm. Sci, 1975, 468-469.

5. Parffit, R. L., R. J. Atkinson and R. St. C. Smart, Soil Sci. Soc. Am. Proc., 1975, 39, 839-841.

6. Parffit, R. L., J. D. Russel and V. C. Farmer, J. Chem. Soc. Faraday I., 1976, 72, 1082-1087.

7. Parffit, R. L. and J. D. Russel, J. Soil Sci., 1977, 28, 297-305.

8. Parffit, R. L. and R. St. C. Smart, J. Chem. Soc. Faraday I., 1977, 73,796-802.

9. Hingston, F. J., R. J. Atkinson, A. M. Posner and J. P. Quirk, Nature (London), 1967, 215, 1459- 1462.

10. Hingston, F. J., R. J. Atkinson, A. M. Posner and J. P. Quirk, J. Soil Sci., 1972, 23, 177-192.

11. Feldkamp, J. R., D. N. Shah, S. L. Meyer, J. L. White and S. L. Hem, J. Pharm. Sci., 1981,70, 638-640.

12. Stumm, W. and J. J. Morgan, Aquatic Chemistry: An Introduction Emphasizing Chemical Equilibria in Natural Waters, 2nd ed., 1981, John Wiley \& Sons, Inc., New York.

13. Davis, J. A., R. O. James and J. O. Leckie, J. Colloid Interface Sci., 1978, 63, 480-499.

14. Aoki, T. and M. Munemori, Water Research, 1982, 25, 793-796.

15. Zachara, J. M., D. C. Girvin, R. C. Schmidt and C.T. Resch, Environ. Sci. Technol., 21, 589594.

16. Parks, G. A., Chem. Rev., 1965, 65, 117-145.

17. Yates, D. E., The Structure of the Oxide/Aqueous Interface, $1975, \mathrm{Ph}$. D. Thesis, University of Melbourne.

18. Nakamoto, K., Infrared and Raman Spectra of Inorganic and Coordination Compounds, 4th ed., 1986, John Wiley \& Sons, Inc. New York.

19. White, R. G., Handbook of Industrial Infrared Analysis, 1964, Plenum Press, New York.'

20. Socrates, G., Infrared Characteristic Group Frequencies, 1980, John Wiley \& Sons, Inc. New York. 